\title{
Early transit of hospitalized myocardial infarction patients
}

\author{
T. Semple, B. O. Williams, T. B. Begg, and J. B. McGuinness \\ From the Cardiac Department, Victoria Infirmary, Glasgow
}

Two hundred and thirty-three patients with definite acute myocardial infarction were transferred directly from a coronary unit to another hospital. There was no morbidity associated with transport and the late mortality was not significantly different from that of patients retained in the parent hospital. Possible developments and advantages resulting from such a policy are discussed.

The substantial number of patients admitted to hospital with acute myocardial infarction often presents a problem in terms of bed occupancy, particularly in acute receiving wards after the initial period of intensive monitoring. The suggestion by Rose (1972) of a period of less than 14 days as an appropriate length of stay in hospital for patients with uncomplicated but definite myocardial infarcts would go some way towards relieving this situation. Such a recommendation would necessitate precise assessment or an attempt at clinical grading of severity, either using a prognostic index (Peel et al., I962) or some more simple system of grading.

Received II January 1974 .

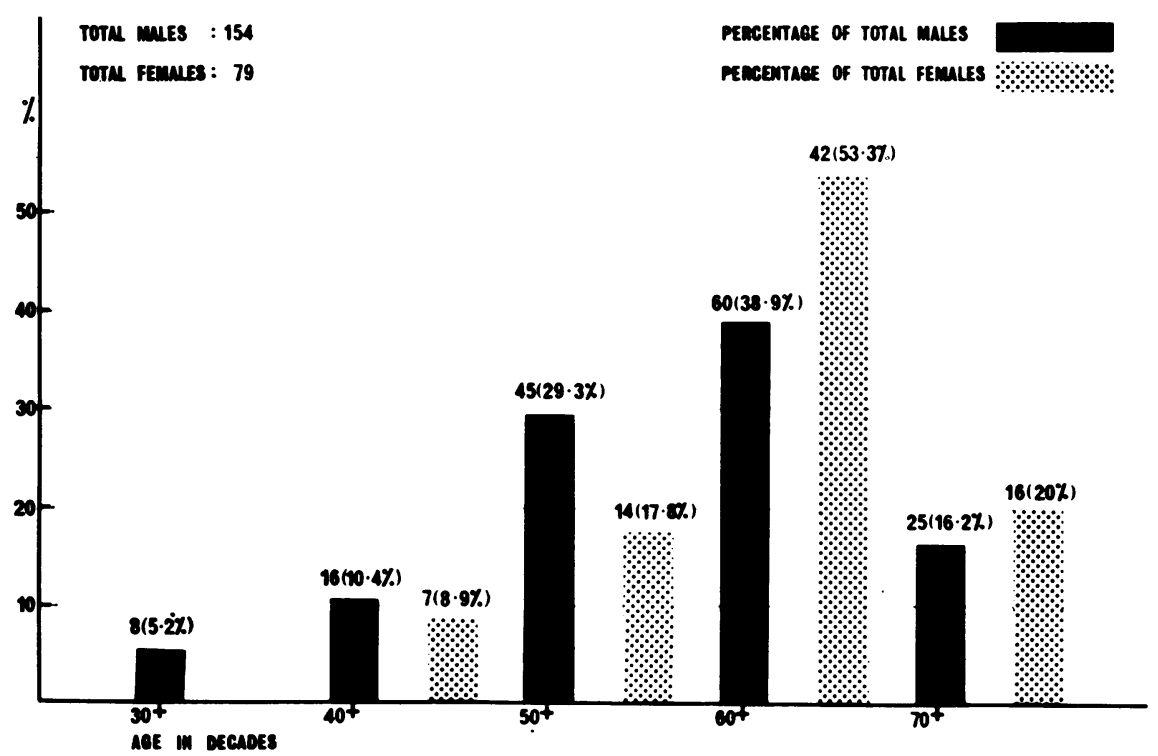

FI G. Age and sex distribution of the 233 transferred myocardial infarction patients. spective survey of the first 233 patients with acute coronary care unit to another hospital, thus bystances arose when several general medical wards cause of structural faults, necessitating reconstruccompleted.

Our report presents data processed from a promyocardial infarction transferred directly from a passing the acute medical wards. The circumof a teaching hospital were temporarily closed betion of a whole ward block. Wards in a neighbouring hospital, newly constructed for geriatric purposes, were used to accommodate coronary and general medical patients, once initial emergency and more intensive nursing and medical care measures were 


\section{Subjects and methods}

During the period 8 December I97I to I5 March 1973 total admissions to the coronary care unit numbered 636 . The main criterion for admission was a presumptive diagnosis of myocardial infarction within the previous 48 hours and there was no age limit. Of the total, 344 $(54 \%)$ had definite acute myocardial infarction as defined by the World Health Organization Report of Fifth Working Group on Ischaemic Heart Disease Registers (197I), and 51 (15\%) of this group died within the coronary care unit.

After treatment in the coronary care unit, patients who had suffered a myocardial infarct were routinely considered for transfer to the other hospital. Sixty (42 men and 18 women) of the 293 surviving patients could not be transferred since no bed was currently available and they were accommodated within the parent hospital. The remaining 233 patients were the subjects of this study. These patients were transferred by conventional two-man ambulance to the neighbouring hospital accompanied by a trained coronary care nurse with a battery powered defibrillator. The nurse continuously monitored her patient using a battery electrocardiograph oscilloscope (Portoscope - Cardiac Recorders Limited). The transfer time between a coronary care bed and the ward bed averaged 20 minutes.

Of these 233 infarct patients, 125 (54\%) were transferred within 72 hours of admission, $190(82 \%)$ within 96 hours, and 209 (90\%) within 120 hours. A histogram (Fig.) demonstrates the age and sex distribution. The majority of men $(55 \%)$ and of women $(73 \%)$ were 60 years and over. Severity as established on discharge from the coronary care unit was defined as follows.

Grade $I$ - patients with definite myocardial infarction with no complications that were considered significant or that demanded treatment. ${ }^{1}$

Grade 2 - patients with myocardial infarction and any of the complications listed in the footnote, ${ }^{1}$ that had settled with treatment.

Grade 3-patients with severe myocardial infarction, with complications ${ }^{1}$ that did not settle with treatment before transfer.

1 Complications which excluded patients from grade I were:

(a) Clinical signs of shock persisting for more than one hour after admission.

(b) Left ventricular failure, manifested by two or more of the following signs: i) dyspnoea at rest, ii) extensive pulmonary crepitations, iii) radiological signs of alveolar or interstitial pulmonary oedema.

(c) Established right heart failure.

(d) Sinus tachycardia over 100 a minute after the first hour.

(e) Supraventricular ectopic beats if: i) five or more per minute, or ii) causing coupling, or iii) in groups of three or more.

(f) Ventricular ectopic beats if: i) five or more per minute, or ii) causing coupling, or iii) in groups of three or more, or iv) multifocal, or $v) R$ on $T$ wave.

(g) Any supraventricular or ventricular dysrhythmia other than ectopic beats.

(h) Heart block of first-, second-, or third-degree.

(i) Systemic or pulmonary embolism.

(j) Definite cardiac enlargement on $x$-ray film.
One hundred and three $(44 \%)$ were in grade $I, I I 0$ $(47 \%)$ in grade 2 , and $20(9 \%)$ in grade 3 .

The severity of myocardial infarction in the nontransit group of 60 patients was as follows: grade I - 30 (50\%), grade $2-23(38 \%)$, and grade $3-7$ (12\%). This distribution is not significantly different from that in the group who were transferred $\left(\chi^{2}=1 \cdot 70 ;\right.$ d. f. $=2$; $\mathrm{P}>0 \cdot 30$ ).

\section{Results}

During transfer there were no clinical or arrhythmic complications reported by the accompanying coronary care unit nurses.

Eleven of the 233 transferred infarct patients, 6 women and 5 men, had required early defibrillation. None of these I I died in hospital after transfer. Another 129 had had some other documented abnormality of rate or rhythm in the coronary care unit, ${ }^{2}$ giving a total incidence of 60 per cent.

After leaving the coronary care unit and while still in the neighbouring hospital, $16(7 \%)$ of the 233 transferred patients died, I I men and 5 women. Ten of these deaths occurred in those under 70 (mortality $5 \%$ ) and 6 in those over 70 (mortality $15 \%$ ). Twelve $(75 \%)$ of the patients who succumbed had had an abnormality of cardiac rate or rhythm in the coronary care unit. ${ }^{2}$

Six (10\%) of the non-transit group died while in the parent hospital ward. Five were in severity grade 2 and one in grade 3 ; ages ranged from 50 to 70 years and death occurred 12 to 21 days after the original admission; 3 died in congestive cardiac failure and 3 died suddenly.

The severity of infarction as assessed in the coronary care unit for all the transferred patients including those who died after transfer is shown in Table I.

The timing of the 16 ward deaths is illustrated in Table 2: 8 of these were sudden, 7 patients died in congestive failure, and one died with a cerebrovascular accident.

Three patients were transferred back to the coronary care unit for a further period of monitoring after successful defibrillation in the satellite hospital ward.

${ }^{2}$ As listed in footnote under (d), (e), (f), (g) or (h).

TABLE I Severity of infarction, assessed before transfer from coronary care unit, of all patients and of those who later died in neighbouring hospital

\begin{tabular}{lrrr}
\hline Severity grading & \multicolumn{1}{c}{2} & \multicolumn{1}{c}{3} \\
\hline Transferred patients & $103(44 \%)$ & $110(47 \%)$ & $20(9 \%)$ \\
Late ward deaths & $2(2 \%)$ & $9(8 \%)$ & $5(25 \%)$ \\
\hline
\end{tabular}

$\star$ For definition of severity gradings see text. 
TABLE 2 Time of death in neighbouring hospital of 16 patients after transfer from coronary care unit.

\begin{tabular}{llllll}
\hline $\begin{array}{l}\text { Time after transfer } \\
\text { in days }\end{array}$ & 1 & 2 & 4 & 5 & $\begin{array}{l}9 \text { days and } \\
\text { over }\end{array}$ \\
\hline No. of ward deaths & I & I & 3 & 4 & 7 \\
\hline
\end{tabular}

The first was a 6r-year-old woman who, having been transferred from the coronary care unit on the 4th day from admission, developed sudden ventricular fibrillation on her I4th day in the ward. She recovered well and was discharged 32 days after initial admission.

The second was a 60-year-old man who after an uncomplicated 72-hour period in the coronary care unit developed ventricular fibrillation and a saddle embolus two days after transfer. He was taken back to the coronary care unit, underwent surgical embolectomy, and remained in cardiac failure until death on the I9th day after his initial hospital admission.

The third was a 47-year-old man with persistent tachycardia who was transferred from the coronary care unit on the 7th day but developed ventricular fibrillation 14 days later. He made a good recovery and was discharged 43 days after his initial admission.

\section{Discussion}

The report demonstrates the comparative safety of transferring patients with myocardial infarction directly from a coronary care unit to another hospital after the initial period of myocardial irritability has settled. It appears that a conventional ambulance is suitable for transit of such patients. The complete absence of any significant arrhythmias in our series if confirmed by other workers might suggest that electrocardiographic monitoring and specialist supervision during such short journeys may even be unnecessary at least in the grade I uncomplicated group. Admittedly our average time of transfer was only 20 minutes from bed to bed; prolonged journeys may be more hazardous.

Follow-up of these patients showed no evidence that such early ambulance transport predisposes to later arrhythmias or sudden late death.

Direct transfer from the coronary care unit to another hospital does bypass and indeed relieves busy emergency receiving beds. The costs of caring for patients in hospitals with modern equipment and highly trained staff are constantly rising and experience such as ours suggests that expensive acute wards are not necessary after the third day for patients with grade I and possibly grade 2 myocardial infarction.

One suggestion, admittedly still tentative and hypothetical, is that all patients with heart attacks could be admitted to a central coronary care unit serving a large district, allowing necessary expertise and equipment to be concentrated in one area. This might ease somewhat the problem of staffing and of staff training and even include facilities and personnel for one or even two emergency domiciliary coronary teams. After the third day mild cases could go to a special coronary after care unit or to a convalescent hospital in their district. Indeed complications after the third day in the mild uncomplicated group are so rare that it might even be logical to be sending a proportion of such patients home and not to a ward elsewhere.

The West Country study (Mather et al., I97I) tended to show that after early arrhythmic problems are solved, the morbidity and mortality of cases of uncomplicated myocardial infarction are probably similar whether managed at home or in hospital, thus supporting this concept of early transfer.

At present there is a tendency towards earlier mobilization, early discharge from hospital, more active rehabilitation, and earlier return to work. Suitable education of patients, relatives, and doctors will be required so that more active policies for patients with uncomplicated heart attacks can be accepted and understood.

\section{Addendum}

Since submitting this communication, 139 further myocardial infarction patients have been transferred from the coronary care unit to the same neighbouring hospital, all without incident making a total of $\mathbf{3 7 2}$ in just under two years.

\section{References}

Mather, H. G., Pearson, N. G., Read, K. L. Q., Shaw, D. B., Steed, G. R., Thorne, M. G., Jones, S., Guerrier, C. J., Eraut, C. D., McHugh, P. M., Chowdhury, N. R., Jafary, M. H., and Wallace, T. J. (197I). Acute myocardial infarction: home and hospital treatment. British Medical fournal, $3,334$.

Peel, A. A. F., Semple, T., Wang, I., Lancaster, W. M., and Dall, J. L. G. (1962). A coronary prognostic index for grading the severity of infarction. British Heart fournal, 24, 745.

Rose, G. (1972). Early mobilization and discharge after myocardial infarction. Modern Concepts of Cardiovascular Disease, 41, 59.

World Health Organization (197I). Ischaemic Heart Disease Registers. Report of the Fifth Working Group. Copenhagen.

Requests for reprints to Dr. T. Semple, Cardiac Department, Victoria Infirmary, Glasgow G42 9TY. 